\title{
Gateway to offending behaviour: permission-giving thoughts of online users of child sexual exploitation material
}

\author{
Danielle G. Kettleborough \& Hannah L. Merdian
}

To cite this article: Danielle G. Kettleborough \& Hannah L. Merdian (2016): Gateway to offending behaviour: permission-giving thoughts of online users of child sexual exploitation material, Journal of Sexual Aggression, DOI: 10.1080/13552600.2016.1231852

\begin{abstract}
The endorsement of permission-giving thoughts, or so-called cognitive distortions, has been discussed as a contributing factor in sexually abusive behaviour. The current study set out to explore the thinking patterns of offenders who have used/downloaded child sexual exploitation material (CSEM), based on a survey of professionals. A thematic analysis elicited four overarching themes, namely the Perceived Nature of Children (perception of children portrayed in CSEM, as well as children in general), Non-sexual Engagement with CSEM (motivating factors that are not inherently sexual in nature), Denial of Harm (perception of the level of harm caused by CSEM), and Expression of a General Sexual Preference (general interest in deviant sexual behaviour). These themes aid to explore the differences and similarities between contact and non-contact offenders and to improve the understanding of the role of permission-giving thoughts in this typology of offending. Results are discussed in terms of their theoretical significance and future implications.
\end{abstract}

KEYWORDS: Child pornography; child sexual exploitation material; cognitive distortions; sex offending; internet sex offending 


\section{Gateway to offending behaviour: permission-giving thoughts of online users of child sexual exploitation material}

The term cognitive distortions was introduced by Beck (1963) in his cognitive model of therapy to describe unfounded or dysfunctional thought content in his patients. For offending behaviour, cognitive distortions are considered offence-supportive beliefs that develop over time and may reinforce the offending behaviour, by internally (and externally) justifying the behaviour (Abel, Becker, \& Cunningham-Rathner, 1984; Bumby, 1996; Burns, 1989; Helmus, Hanson, Babchishin, \& Mann, 2013; Mann \& Marshall, 2009; Neidigh \& Krop, 1992; Ó Ciardha \& Gannon, 2011; Ó Ciardha \& Ward, 2013; Pollack \& Hashmall, 1991). Numerous terms have been coined to describe what are perhaps most commonly known as cognitive distortions, including exaggerated or irrational thoughts, beliefs, justifications, schemas, excuses, rationalisations, denials, and minimisations (e.g. Blumenthal, Gudjonsson, \& Burns, 1999; Marshall, Marshall, \& Kingston, 2011; Navathe, Ward, \& Gannon, 2008). For the purpose of the present study, the authors have opted to instead use the term "permission-giving" thoughts, or statements, to refer to "cognitive distortions" or "offence-supportive beliefs". Permission-giving thoughts are defined as statements that may increase the individual's risk of translating internal motivation into offending behaviour, but may include statements that may not be defined as "distorted". An example of this, relating to offences concerning child sexual exploitation material (CSEM), is the following statement: "Looking at CSEM is not as bad as touching a child".

Whilst this statement portrays a permission-giving thought; it may not be "distorted", in the sense that not being "as bad" could be reflective of the legal penalties attached to CSEM offending in comparison to a contact sexual offence against a child. Endorsement of permission-giving statements have been linked to the commission of sex offending behaviour and are considered a crucial factor in the risk of reoffending (Andrews \& Bonta, 2006; Ward \& Beech, 2006); particularly sex offending (Beech, Bartels, \& Dixon, 2013; Thornton, 2002). As a result, they are frequently targeted in the assessment and treatment of sex offenders (Beech \& Mann, 2002; Gannon \& Polaschek, 2006; Gannon, Ward, \& Polaschek, 2004; Helmus et al., 2013; Marshall, Anderson, \& Fernandez, 1999; Ó Ciardha \& Gannon, 2011). However, the aetiology of permission-giving thoughts is not clear; there are conflicting theories as to whether they are offence-supportive attitudes developed in childhood (Ward \& Keenan, 1999), thoughts that are formed during offending behaviour, or justifications that are developed post hoc (Gannon \& Polaschek, 2006; Maruna \& Mann, 2006), and as such, their 
role in offending behaviour and desistance from it has been challenged in the broader literature (Maruna \& Mann, 2006; Merdian, Curtis, Thakker, Wilson, \& Boer, 2014).

According to Beck's (1963) cognitive approach, permission-giving statements result from an individual's maladaptive schemas, a set of interlocking beliefs that develop in early childhood and influence the processing of new information. These schemas are used, for example, in the interpretation of people's behaviour and in forming predictions about the world (Gannon \& Polaschek, 2006; Ward, 2000). For child sex offenders, one of the most prominent conceptual models was proposed by Ward and Keenan (1999), suggesting that their permission-giving statements emerge from five specific schemas, or implicit theories, about the nature of their victims, the world, and themselves.

- Children as sexual beings: This schema describes the belief that people, including children, are sexual beings, motivated by a desire for pleasure. Children are thus believed to have the capacity to make informed decisions about engaging in sexual activity with adults. Endorsement of this implicit theory can lead to an interpretation of children's everyday behaviour as revealing sexual intent.

- Entitlement: This schema describes the belief that some people are more important than others and therefore have a right to assert their needs. Offenders who endorse this implicit theory may view themselves as of greater importance than children and therefore have a "right" to have sex with children, whenever they desire.

- Dangerous world: This schema describes the belief that the world is a dangerous place and it is thus necessary to achieve dominance. Individuals that endorse this implicit theory may perceive adults as untrustworthy and refer to children as the only "safe" sexual partners.

- Uncontrollability: This implicit theory describes the belief that there are factors beyond an offender's control that underlie their sexually abusive behaviour. Individuals who endorse this implicit theory may perceive they cannot be held responsible for their sexually abusive behaviour as it is considered an urge or drive that cannot be controlled.

- Nature of harm: This implicit theory describes the belief that sexual activity in itself is beneficial and unlikely to cause harm. This belief can lead to a judgement that children are not harmed by sex with an adult, and that any distress a child experiences is a function of additional physical force or the way in which people respond to the abuse, not the act of sexual abuse itself. Ward and Keenan 
postulated that for child sex offenders, children's behaviour is likely to be interpreted in sexual terms, based on the underlying implicit theory, and as a product of this, permission-giving statements are generated that enable the offending behaviour.

\section{The emergence of non-contact sex offending as a research area}

Research on permission-giving thoughts and theoretical explanations of sex offending against children has recently evolved into the area of CSEM Offenders (CSEMOs). A substantial rise in convictions for CSEM-related offences (Radford et al., 2011) has consequently resulted in an increase in research on CSEMOs (Babchishin, Hanson, \& Hermann, 2011; Babchishin, Hanson \& VanZuylen, 2015; Seto, Hanson, \& Babchishin, 2011). One of the most widely researched questions is whether CSEMOs are a distinct type of sex offender from contact sex offenders (CSOs) and comparison studies have identified some differences regarding psychological and offence-related variables (Babchishin et al., 2011; Elliott, Beech, \& Mandeville-Norden, 2012; Lee, Li, Lamade, Schuler, \& Prentky, 2012; McCarthy, 2010). However, CSEMOs do not present as a homogeneous group: CSEM use has been linked to a range of functions beyond sexual satisfaction, such as financial gain or using the material to desensitise a potential contact victim (Caple, 2008; Merdian, Wilson, Thakker, Curtis, \& Boer, 2013; Quayle, Erooga, Wright, Taylor, \& Harbinson, 2006; Seto, Reeves, \& Jung, 2010; Surjadi, Bullens, Van Horn, \& Bogaerts, 2010; Taylor, Holland, \& Quayle, 2001; Taylor \& Quayle, 2003, 2005), and research on the offence motivations of CSEMOs has revealed a range of motivators for viewing CSEM, such as a sexual interest in children, indiscriminate sexual interests, or unmet emotional needs (Merdian, Curtis, Thakker, Wilson, \& Boer, 2013; Seto et al., 2010). Based on research conducted on online groomers (Briggs, Simon, \& Simonsen, 2011), Merdian, Curtis, et al. (2013) suggested a distinction of CSEMOs based on a "contact-driven" and "fantasy-driven" typology. Contactdriven offenders are considered more similar to the profile of a contact sex offender, for example, they may use CSEM as a means to desensitise their victim for future contact offences or use CSEM as a substitute for contact offending; thus, they are considered more likely to escalate from CSEM viewing to contact sex offending. On the other hand, fantasydriven offenders are considered low risk of committing a contact sex offence, as the function of their usage is on exploring their sexual fantasies or the offender may enjoy the collecting, distributing, and trading aspects of CSEM usage. This distinction between fantasy-driven and contact-driven offending appears conceptually attractive for the group of CSEMOs, and thus may find application in differing permission-giving statements between the offender 
subgroups. Following this theoretical concept, it is hypothesised that contact-driven CSEMOs may present with similar permission-giving thoughts to contact sex offenders, whereas the fantasy-driven offenders are likely to present with differing, fantasy-driven cognitions.

\section{The endorsement of permission-giving thoughts amongst CSEMOs}

There are two streams of research on the endorsement of permission-giving statements amongst CSEMOs, namely, the application of existing measures that were originally developed for CSOs, and the identification of CSEM-specific permission-giving statements. With regards to the former, measures used in the research to date include the MOLEST Scale (Bumby, 1996; in Neutze, Seto, Schaefer, Mundt, \& Beier, 2011), the Abel and Becker's Cognitions Scale (ABCS; Abel et al., 1984; in Merdian et al., 2014), the Victim Empathy Distortion Scale (Beckett \& Fisher, 1994; in Elliott, Beech, Mandeville-Norden, \& Hayes, 2009) and the Children and Sex Cognitions Questionnaire (Beckett, 1987; in Elliott et al., 2009). Overall, in these studies, CSEMOs were found to endorse permission-giving statements to a lower degree than CSOs (see also Howitt \& Sheldon, 2007). This could suggest that CSEMOs are generally less likely to endorse permission-giving statements compared to CSOs, or endorse cognitions of a different quality than CSOs that are not included in the existing scales.

In response to the latter aspect, more specific measures have been developed for CSEMOs, for example, the Internet Behaviours and Attitudes Questionnaire (IBAQ; O'Brien \& Webster, 2007) and the Children and Sexual Activities Inventory (C\&SA; Howitt \& Sheldon, 2007). However, both of these measures were developed based on existing measures of permission-giving statements, and thus could potentially face some of the problems of previous measures that are capturing permission-giving thoughts relating to CSOs. An example of this is the Victim Empathy Distortion Scale (Beckett \& Fisher, 1994) that was utilised in the development of the IBAQ (O'Brien \& Webster, 2007), and the MOLEST Scale (Bumby, 1996) in the development of the C\&SA (Howitt \& Sheldon, 2007). In addition, the items for the C\&SA were specifically refined and classified into Ward and Keenan's (1999) five implicit theories of contact sex offending. Results from the C\&SA (Howitt \& Sheldon, 2007) highlighted some potential differences in the cognitions between CSEMOs and CSOs, such as the finding that CSEMOs were more likely to endorse items relating to the implicit theory of Children as Sexual Beings. However, these findings were not confirmed in a recent study on the C\&SA; Merdian et al. (2014) found little support of these items amongst CSEMOs, with contact sex offenders scoring significantly higher on items relating to Justification, Children as Sexual Agents, and Power and Entitlement. In addition, 
both the IBAQ and the C\&SA presented with poor psychometric properties, which do not allow for firm conclusions at this stage.

In summary, the limited research available on the endorsement of permission-giving statements amongst CSEMOs has suggested that as a group, they are less likely to endorse permission-giving statements regarding children and sexual behaviour when traditional scales are used. However, research on the C\&SA has provided some indication that Ward and Keenan's (1999) implicit theories may have some value for CSEMOs, though that CSEMOs may further endorse permission-giving statements of a differing quality from CSOs. Yet, so far, no scale has been developed, without reference to existing scales for contact sex offending, to measure the endorsement of potentially offence-specific cognitions of CSEMOs. In addition, it has been suggested that subtypes of CSEMOs may be differentiated, such as the distinction between "contact-driven" and "fantasy-driven" CSEMOs outlined above (Briggs et al., 2011; Merdian, Curtis, et al., 2013). It was hypothesised that this could be expressed in the endorsement of differing cognitions amongst the CSEM subtypes; however, the existing scales do not have the sensitivity to capture the potential heterogeneity amongst CSEMOs.

The present study aims to fill the gap in the current research by exploring permissiongiving statements specifically relating to CSEMOs. Given that the reviewed research highlighted the potentially problematic nature of a deductive approach based on the existing body on cognitive distortions relating to children and sex, the present study aimed to identify the distinctive permission-giving statements that may be endorsed by CSEMOs via an inductive approach, by asking professionals to provide qualitative accounts based on their experience of working with this offender group. Specifically, professionals were asked about CSEM-specific "thinking patterns", which will later be validated in a CSEMO sample (not part of the current study). In order to enhance the understanding of the cognitions of CSEMOs, the research focus was on professionals rather than offenders themselves, to complement and extend the existing work that employed CSEMO samples (Howitt \& Sheldon, 2007; Merdian et al., 2014) and given that people do not always have insight into their own cognitions (Wilson, 2004). Gaining an initial qualitative understanding from professionals represents the first stage in a structured development process, followed by its validation with a CSEMO sample. Overall, this approach mirrors the development process used by Ward and Keenan (1999).

\section{Method}

\section{Participants}


Sixteen professionals who work with CSEMOs in different capacities were recruited using chain sampling, starting with the authors' professional network. Table 1 provides a summary of the participants' gender, profession, and years of experience working with CSEMOs.

Table 1.

Participants' Demographic Information concerning Gender, Profession, and Years of Experience working with CSEMOs

\begin{tabular}{|c|c|c|}
\hline Profession & Gender & $\begin{array}{l}\text { Years of } \\
\text { Experience }\end{array}$ \\
\hline Consultant Psychologist & Male & $0^{1}$ \\
\hline Research Scholar & Male & 6 \\
\hline Senior Psychologist & Male & 5 \\
\hline Consultant Psychiatrist & Male & $0^{1}$ \\
\hline Psychologist & Male & 5 \\
\hline Senior Forensic Psychologist & Female & 13 \\
\hline Consultant Clinical and Forensic Psychologist & Male & 16 \\
\hline Clinical Forensic Psychologist & Male & 15 \\
\hline Consultant Forensic and Clinical Psychologist & Female & 3 \\
\hline County Risk Management Specialist (Social Worker) & Male & 5 \\
\hline Probation Officer & Male & 4 \\
\hline Treatment Manager, Community Sex Offender Programmes & Female & 9 \\
\hline Probation Officer & Male & 3 \\
\hline
\end{tabular}

Three participants (19\%) did not provide demographic information, reasons unstated. Overall, the professionals consisted of seven Psychologists, three Probation Officers, one Psychiatrist, one Social Worker, and one Researcher, with experience ranging from conducting occasional assessments to facilitating weekly group treatment programmes. All participants were recruited from Commonwealth countries.

\section{Procedure}


Participants were required to complete a survey, either electronically or by hand, to "explore the thinking patterns of child pornography offenders". First, participants were asked open-ended questions which required them to describe the thinking patterns of CSEMOs, based on their experience working with this offender group, and to describe the perceived differences in the thinking patterns of CSEMOs and CSOs. Second, in response to the findings of Howitt and Sheldon (2007), participants were presented with a short description of Ward and Keenan's (1999) five implicit theories and asked to rate the applicability of those for CSEMOs, using a six-point Likert scale (very strongly agree to very strongly disagree). They were also asked to identify any additional schemas specific to CSEMOs. This research was conducted in accordance with the Code of Ethics and Conduct of the British Psychological Society (2009).

\section{Data analysis}

The data analysis consisted of two parts: the initial theme extraction, and theme validation, and the final definition of the themes. All survey responses were analysed using Inductive Thematic Analysis, a qualitative approach within an essentialist/realist framework emphasising semantic themes, following the procedure outlined by Braun and Clarke (2006). Phase one of the analysis involved repeated reading of the survey responses, which was followed by initial coding of each piece of data. Following this, potential relationships between data extracts were identified and sorted into potential themes and subthemes.

Once initial themes were identified, the data extracts were reviewed until they provided an overall coherent pattern and representation of the given theme. The entire data was re-read in order to ascertain if the themes reflected the data set as a whole. The final phase of analysis involved defining the themes, by providing a detailed analysis of the narrative within each theme. At this stage, two independent researchers read the collated data and theme definitions to further refine the themes and ensure they presented a coherent representation. Furthermore, the themes were explored in terms of their relationship to Ward and Keenan's (1999) implicit theories.

\section{Results}

Participants were initially asked if they thought the thinking patterns of CSEMOs differed from those who committed a contact sex offence against a child, which was asserted by all 16 participants. Participants were then asked to rank the applicability of Ward and Keenan's implicit theories; Table 2 shows the distribution of the dichotomised responses (i.e., the six response categories collapsed into either "agree" or "disagree"). 
The participants showed mixed agreement as to whether Ward and Keenan's implicit theories could be applied to CSEMOs, highlighting that this model is not directly applicable to CSEMOs. The implicit theories Children as Sexual Beings and Nature of Harm received the highest levels of agreement, suggesting that participants perceived the cognitions of CSEMOs and CSOs to be comparable within these theories. However, participants agreed that the implicit theories of Dangerous World and Uncontrollability did generally not apply for CSEMOs. Overall, this evidence suggests that Ward and Keenan's theoretical model, as a whole, may not apply to CSEMOs, and thus further assert the notion that CSEMOs might endorse differing permission-giving statements from CSOs.

Table 2.

Professionals' $(n=16)$ level of agreement to the application of Ward and Keenan's (1999) implicit theories to Child Sexual Exploitation Material Offenders

\section{Implicit Theory $\quad \%$ Agreement (n)}

Children as Sexual Objects $68.75(11)$

\begin{tabular}{ll}
\hline Entitlement & $56.25(9)$ \\
\hline Dangerous World & $37.5(6)$ \\
\hline Uncontrollability & $43.75(7)$ \\
\hline Nature of Harm & $18.75(3)$ \\
\hline
\end{tabular}

Thematic Analysis of the participants' responses regarding the thinking patterns of CSEMOs resulted in four initial themes with 10 subthemes. The four overarching themes were identified and labelled as Perceived Nature of Children, Non-sexual Engagement with CSEM, Denial of Harm, and Expression of a General Sexual Preference. For each theme, a number of subthemes were identified, portraying variants of the main theme (Table 3). 
Table 3.

Themes and Subthemes regarding the Permission-Giving Thoughts of Child Sexual

Exploitation Material Offenders based on Professionals’ Responses

Theme Subtheme Definition

\begin{tabular}{|c|c|c|}
\hline \multirow[t]{3}{*}{$\begin{array}{l}\text { Perceived } \\
\text { Nature of } \\
\text { Children }\end{array}$} & $\begin{array}{l}\text { Children as Fantasy } \\
\text { Characters }\end{array}$ & $\begin{array}{l}\text { Children portrayed in CSEM are not } \\
\text { "real" children, CSEM is a fantasy } \\
\text { world }\end{array}$ \\
\hline & Children as Actors & $\begin{array}{l}\text { Children are capable of "acting" } \\
\text { sexually sophisticated }\end{array}$ \\
\hline & $\begin{array}{l}\text { Children as Sexual } \\
\text { Beings }\end{array}$ & $\begin{array}{l}\text { Children have the capacity and } \\
\text { understanding to enter into a sexual } \\
\text { relationship with an adult }\end{array}$ \\
\hline \multirow[t]{3}{*}{$\begin{array}{l}\text { Non-sexual } \\
\text { Engagement } \\
\text { with CSEM }\end{array}$} & $\begin{array}{l}\text { Reinforcement } \\
\text { through Collecting } \\
\text { and Trading } \\
\text { Behaviours }\end{array}$ & $\begin{array}{l}\text { Enjoyment stems from the collection } \\
\text { and management aspects of CSEM }\end{array}$ \\
\hline & $\begin{array}{l}\text { Uncontrollability of } \\
\text { Offending Behaviour }\end{array}$ & $\begin{array}{l}\text { There are factors beyond an individual's } \\
\text { control that underlie their CSEM } \\
\text { offending }\end{array}$ \\
\hline & $\begin{array}{l}\text { CSEM as a means for } \\
\text { Emotion Regulation }\end{array}$ & $\begin{array}{l}\text { CSEM is used to elicit positive } \\
\text { emotions, or alleviate negative feelings }\end{array}$ \\
\hline \multirow[t]{2}{*}{$\begin{array}{l}\text { Denial of } \\
\text { Harm }\end{array}$} & $\begin{array}{l}\text { Denial of Role in the } \\
\text { Sexual Abuse of } \\
\text { Children }\end{array}$ & $\begin{array}{l}\text { Viewing CSEM causes little harm to the } \\
\text { children portrayed in CSEM due to the } \\
\text { offender having no direct physical } \\
\text { contact }\end{array}$ \\
\hline & $\begin{array}{l}\text { Child Sexual Abuse as } \\
\text { a Societal Construct }\end{array}$ & $\begin{array}{l}\text { Any distress a child experiences is as } \\
\text { consequence of society's negative } \\
\text { response, not the abuse itself }\end{array}$ \\
\hline \multirow[t]{2}{*}{$\begin{array}{l}\text { Expression } \\
\text { of a General } \\
\text { Sexual } \\
\text { Preference }\end{array}$} & $\begin{array}{l}\text { CSEM as } \\
\text { Manifestation for } \\
\text { Voyeuristic Interests }\end{array}$ & $\begin{array}{l}\text { Enjoyment stems from the observation } \\
\text { and secrecy of looking at sexual } \\
\text { activity, not specifically related to } \\
\text { children }\end{array}$ \\
\hline & $\begin{array}{l}\text { CSEM as Part of a } \\
\text { Preference for }\end{array}$ & $\begin{array}{l}\text { A general interest in sexually deviant } \\
\text { content, not a refined interest in CSEM }\end{array}$ \\
\hline
\end{tabular}




\section{Perceived nature of children.}

This overarching theme is concerned with the professionals' feedback on how they report CSEMOs to perceive the children portrayed in CSEM, as well as their view of children in general. Three distinct subthemes were identified, relating to Children as Fantasy Characters, Children as Actors, and Children as Sexual Beings.

Children as Fantasy Characters: This subtheme refers to the perception that children portrayed in CSEM are not "real" children. Professionals reported that CSEMOs who endorse this belief view CSEM as a fantasy or imaginary world and there is no connection made between the portrayed children and children in "real life". Statements from the participants' data suggested that CSEMOs “do not perceive the activities they view as essentially 'real', or the children in the images as 'real' people" (Participant 21) or that CSEMOs "dont [sic] have any real victims" (Participant 1).

Children as Actors: This subtheme refers to the perception that children are capable of acting in a sexually sophisticated way. Professionals reported that CSEMOs who endorse this belief do not generally view children as sexual beings, however, asserted that they (temporarily) portray a role meant to be sexually arousing. For example, Participant 2 stated that CSEMOs view the children in the images as "actors" (for want of a better term). Hence, they may be able to view the "child in the image" as sexually sophisticated, based on their performance (as an “actor”). So smiling, seemingly compliant “on screen” children are seen as sexually sophisticated, but the offender does not view children en masse as seually [sic] sophisticated.

Children as Sexual Beings: Professionals reported that CSEMOs who endorsed this belief perceive children as sexual beings with the capacity and understanding to enter into a sexual relationship with an adult. Here, children are generally considered sexually sophisticated. This subtheme shows similarity to Ward and Keenan's (1999) implicit theory Children as Sexual Beings. Examples of this theme come from Participant 3 who suggested CSEMOs "think the children are enjoying the sexual behaviour" and Participant 1 who gave examples of CSEMOs beliefs, such as "kids really want sex, kids are seductive". Participant 
15 explained that the perception of a child's sexual enjoyment comes from statements by the offenders such as "they were smiling, they appeared happy".

\section{Non-sexual engagement with CSEM}

This theme concerns motivating factors for engaging in CSEM offending that are not inherently sexual in nature. Sexual arousal may be secondary, or non-existent. Three subthemes were identified, relating to Reinforcement through Collecting and Trading Behaviours, Uncontrollability of Offending Behaviours, and CSEM as a Means for Emotion Regulation.

Reinforcement through Collecting and Trading Behaviours: This subtheme relates to the professionals' opinion that there are some CSEMOs who primarily engage in CSEM offending due to the enjoyment stemming from the collection and management aspects of CSEM. For example, these individuals may enjoy the collecting and sorting of CSEM, facilitating trading systems, managing servers or the fact that they are doing something illegal. Individuals may report not being sexually aroused by the content of CSEM. Examples of this subtheme come from Participant 3 who explained: "They tend to enjoy the act of collecting more than the images themselves" and that "actual sexual interest in children seems secondary to the frisson of the material being illegal". Participant 3 further suggested that CSEMOs may get their "enjoyment from managing the servers and encryption protocols".

Uncontrollability of Offending Behaviour: This subtheme is purposefully likened to Ward and Keenan's (1999) implicit theory of Uncontrollability as it describes the belief that there are factors beyond an offender's control that underlie their CSEM offending. Professionals reported that these CSEMOs perceive the world as uncontrollable and believe that people have no control over their own mental states or sexual preference, for example, because they were "primed" to them during childhood. Factors such as stress, alcohol, or addiction may be blamed for the offending behaviour. Participant 2 suggested that CSEMOs "will often blame various factors outside of their control", asserted by Participant 15 who stated that "Internet offenders often seem to report feeling that many aspects of their lives + behaviour felt out of control, for example, describing internet sexual behaviour as an 'addiction'".

CSEM as a Means for Emotion Regulation: Professionals reported that some individuals view CSEM as a means to elicit positive emotions, or alleviate negative feelings relating to stress or loneliness. Professionals further reported that CSEMOs who endorse this pattern of thinking may engage in CSEM offending as a means to overcome interpersonal 
deficits and feel a sense of belonging, alleviating feelings of isolation. Additionally, this subtheme encompasses those individuals that may consume CSEM in order to feel a sense of power or control. Examples of this theme were stated by Participant 13 who suggested that CSEM is consumed to "achieve emotional regulation; overcome intimacy deficits" and Participant 15 who discussed CSEMOs having "intimacy problems, generally wanting to make themselves 'feel' better" and "Viewing images is a way of increasing feelings of wellbeing, a 'soothing' strategy and a way of alleviating feelings associated with negative selfbeliefs".

\section{Denial of harm}

This theme refers to the perception of the level of harm caused by CSEM, both by the act of viewing CSEM and the level of risk posed by the CSEMOs themselves. Two subthemes were identified, relating to Denial of Role in the Sexual Abuse of Children and Child Sexual Abuse as a Societal Construct.

Denial of Role in the Sexual Abuse of Children: This theme can be likened to Ward and Keenan's (1999) Nature of Harm, suggesting that there are varying degrees of harm and that sexual activity in itself is unlikely to harm a person, including children. Professionals report that CSEMOs who endorse this belief may suggest that viewing CSEM is causing little harm to the children portrayed in CSEM because the offender does not have any direct physical contact with the victim. Regardless of the degree of harm that a child experiences within CSEM, because there is no direct physical contact between the child and the person viewing the material, CSEMOs are said to cause no harm. Professionals report that CSEMOs who endorse this belief are also likely to distance themselves from other offenders, especially contact offenders, due to their perceived lack of involvement in the abuse of children. Participant 2 suggested that CSEMOs "do not see viewing images as harmful to the child in the image". CSEM viewing is perceived as "It does not cause any harm" (Participant 6) or that "there's no real harm done" (Participant 13), further stating "the children in the images were not harmed" (Participant 15).

Child Sexual Abuse as a Societal Construct: This subtheme can be likened to the second part of Ward and Keenan's (1999) Nature of Harm that assumes children are not necessarily harmed by the physical or psychological consequences of the sexual activity but that any experienced distress is resultant from society's negative response. Society can therefore be blamed for any distress associated with CSEM, as the offenders consider themselves "not doing anything morally wrong" (Participant 11). 
This subtheme was also evident in Participant 7 who explained CSEMOs "tend to not think they are harming the children and distance themselves". Participant 2 explained that they have used a "moral disengagement questionnaire" in their own practice.

\section{Expression of a general sexual preference}

The overarching theme of expression of a general sexual preference relates to professionals' feedback that implies CSEM offending has arisen due to the individual having a general interest in deviant sexual behaviour, and not a specified sexual interest in children. Two subthemes were identified, CSEM as Manifestation for Voyeuristic Interests and CSEM as part of a Preference for Sexually Deviant Content.

CSEM as Manifestation for Voyeuristic Interests: Professionals reported that CSEMOs who endorse this subtheme find enjoyment from the observation and the secrecy of looking at sexual activity, not specifically related to sexual activity with children. These individuals may describe themselves as "browsers". Examples of this subtheme come from Participant 6 who suggested "Typically the thinking pattern reflect a voyeristic [sic] focus" and Participant 13 who stated "A large proportion of non-contact offenders are 'voyeurs' or 'browsers' of illicit pornography”.

CSEM as Part of a Preference for Sexually Deviant Content: This subtheme refers to professionals reporting that CSEMOs describe having a general interest in sexually deviant content but not a refined interest in CSEM or exclusive sexual preference for children. These individuals have a sexual preference for a wide range of sexually deviant material, including bestiality or non-consensual sexual activity. This theme was found in Participant 3 who suggested "most collections would include a wide range of odd material, including anime, bestiality and rape images, suggesting a general interest in marginal or extreme behaviour rather than pedophilia per se" and Participant 12 who suggested CSEMOs have a "desire to access graphic visual materials".

To summarise, a total of 10 diverse subthemes were identified from the thematic analysis, which were subsumed into four overarching themes. However, based on the scope of this study it is difficult to surmise the exact nature, and hierarchy, of each theme and how they interact with each other; it is likely that a distinction between broader implicit theories and resulting permission-giving thoughts can be established amongst the themes.

\section{Discussion}

Previous research on the endorsement of permission-giving thoughts of offenders who have used CSEM has suggested that offenders hold either fewer, or different, cognitions in comparison to those endorsed by child contact sex offenders (Babchishin et al., 2015; Bates 
\& Metcalf, 2007; Elliott et al., 2009; Webb, Craissati, \& Keen, 2007). However, the research to date has focussed primarily on existing scales that have been developed and validated for CSOs (Howitt \& Sheldon, 2007; O’Brien \& Webster, 2007), and that may not encompass cognitions specific to the situation of CSEMOs. The present study thus aimed to explore and identify permission-giving thoughts that specifically relate to CSEMOs. A range of CSEMspecific themes were elicited from professionals working with this offender group.

Previous research had indicated that Ward and Keenan's implicit theories do not translate for CSEMOs; however, some endorsement was found for Children as Sexual Beings amongst CSEMOs (Howitt \& Sheldon, 2007). Using items from Howitt and Sheldon's cognitive distortion measure, Merdian et al. (2014) found that CSEMOs scores were generally lower on these items than CSOs, and significantly so on items relating to Justification (e.g. "A man is justified in having sex with his children or step-children, if his wife does not like sex"), Children as Sexual Agents (e.g. "A child will never have sex with an adult unless the child really wants to"), and Power and Entitlement (e.g. "A person should have sex whenever it is needed"). When the participants in the current study were asked to rate the applicability of Ward and Keenan's implicit theories for CSEMOs, Children as Sexual Beings and Nature of Harm received the highest levels of agreement while Dangerous World and Uncontrollability were not considered applicable for CSEMOs. The identification of Children as Sexual Beings implies that for at least some CSEMOs there is a sexual interest in children, which sits with previous research finding higher sexual interest in children amongst CSEMOs, when compared to CSOs (Babchishin et al., 2015). However, agreement with Nature of Harm implies that there is some denial in the harm of their offending behaviour, which could be as a result of antisocial personality tendencies which is found to be higher amongst CSOs (Babchishin et al., 2015). Thus, the current study is in line with existing research findings. In the next part of this study, professionals were asked to identify thinking patterns specifically related to CSEM offending. Here, four core themes regarding the permission-giving thoughts of CSEMOs were identified which again shows some overlap with Ward and Keenan's (1999) implicit theories, in particular for Children as Sexual Beings (Children as Sexual Beings), Uncontrollability of Offending Behaviour (Uncontrollability), and Denial of Harm (Nature of Harm). It is noteworthy that the thematic analysis did not elicit a theme similar to Ward and Keenan's (1999) implicit theory of Dangerous World. In the participants' rating, the Dangerous World schema received the lowest level of agreement of applicability to CSEMOs. Professionals were specifically prompted to provide information regarding this implicit theory, yet no comments were raised regarding its prevalence in 
CSEMOs. In its essence, the Dangerous World schema has two components: It refers to a perception of the world as a hostile place where dominance needs to be achieved, which refers to the entitlement and antisociality behaviours discussed above, and secondly, it refers to emotional congruence with children, considering children as a "safe" sexual partner amongst untrustworthy adults. With regards to emotional congruence with children, Babchishin et al. (2015) reported that while CSEMOs and CSOs were similar regarding victim empathy, CSOs were found to display significantly stronger emotional identification with children. This finding appears to be supported by the present research in that the Dangerous World schema was found not applicable to CSEMOs, suggesting low emotional identifications with children amongst CSEMOs.

In their recent meta-analysis on CSEMOs, Babchishin et al. (2015) identified the main predictors of cross-over from CSEM consumption to committing a contact sex offence: A sexual interest in children, access to children, high levels of antisociality, and few psychological barriers to acting on one's sexually deviant interests. Again, although there was no offender data collected in this study, it is possible to theorise that an offender with these risk characteristics may endorse the above themes of considering children as sexual beings due to a sexual interest in children, the denial of harm of their sexual actions (either due to a lack of empathy or a disregard for the other person; i.e., antisociality) and the uncontrollability of their behaviour (lack of inhibition on acting on one's sexual interest). The current study also resulted in a number of offence-specific themes that mirror the current empirical and theoretical developments in the field. In the original Three-dimensional Model of CSEM Offending, Merdian, Curtis, et al. (2013) proposed that CSEM offending originates from four motivations: (1) A sexual interest in children, (2) a general deviant sexual interest, (3) financial motivation, or (4) other, such as the collecting nature of CSEM engagement. The current study found evidence of all four motivational types: While the Perceived Nature of Children clearly refers to a sexual interest in children, CSEMOs appear to have a more distinguished perception of children beyond their perceived sexual nature, including their perception as fantasy characters and actors. The child is thus not perceived as a sexual being per se but instead is perceived in a role, similar to the actors in legal pornographic material. The second motivation, a general deviant sexual interest, is clearly identified in the last theme identified in this paper, with CSEM considered as a manifestation for voyeuristic interests (which thus may generalise over different types of visually arousing material) and CSEM as part of a preference for sexually deviant content. Such a viewer will also have other types of illegal material, such as bestiality, on their hard drive, potentially in a higher ratio than would 
be expected from unselected downloading behaviour. Finally, Merdian, Curtis, and colleagues proposed two non-sexual motivations for CSEM usage, conceptualising that the offending behaviour was not driven by sexual desires, and that sexual arousal may be secondary to the motivating factor, or non-existent. The engagement in CSEM for non-sexual reasons is a controversial topic; however, previous research on the offence motivations of CSEMOs has already pointed to the existence of non-sexually motivated offending (e.g. Seto et al., 2010; Surjadi et al., 2010). The current study suggests that for some, CSEM appears to hold attraction due to the collecting and sorting aspect of the behaviour (see also Seto et al., 2010; Taylor \& Quayle, 2003). This study also suggests that CSEM could be a means for emotion regulation, a theme that strongly emerged when offenders were asked directly about their offence motivations (Merdian, Wilson, et al., 2013). It thus appears that for some, individual CSEM consumption may have a soothing or distracting quality beyond its sexual components. These findings suggest not only the existence of two potential offender subgroups of contact-driven versus fantasy-driven offenders but further point to the heterogeneity amongst the latter group which warrants further research into the idiosyncrasies of this offender subtype. It is possible that the findings from this study could have implications in establishing the distinction between fantasy-driven and contact-driven offending, with different themes reflecting these distinctions. However, since these themes were developed from professional opinion, this hypothesis would need to be validated on a CSEMO sample.

The results support growing research that suggests CSEMOs may be a distinct group of sex offenders, in relation to their cognitions, and could support the hypothesis that there may be differing typologies of CSEMOs (Babchishin et al., 2011; Seto et al., 2011). The diverse range of themes captures the complexity and heterogeneity of the cognitions in CSEMOs. Whilst research to date has suggested that CSEMOs endorse significantly less permission-giving thoughts compared to CSOs (Babchishin et al., 2011; Bates \& Metcalf, 2007; Elliott et al., 2009; Webb et al., 2007), the current research appears to support the alternative hypothesis, that CSEMOs may hold qualitatively different cognitions to CSOs, which were not included in the measures used in previous research on the cognitions of CSEMOs (Bates \& Metcalf, 2007; Beckett, 1987; Bumby, 1996; Elliott \& Beech, 2009). Again, it is thus vital to validate these themes on a CSEMO sample.

\section{Limitations}

The themes elicited in this study were based on the expertise of professionals working with CSEMOs, as opposed to knowledge obtained from CSEMOs themselves. This could be 
identified as a limitation of the present study, as the offenders themselves may have provided a more accurate expert account of their own cognitions. However, the consequences of selecting CSEMOs themselves would raise a number of concerns regarding potential bias and social desirability. Nevertheless, there is also the possibility of potential bias in the professionals' portrayal of CSEMOs: Professionals will be influenced by the individual CSEMOs they encountered in their work, which will be biased according to the setting they are employed in. In addition, professionals will be duly influenced by the research published in the field. Furthermore, the reliability and validity of professional judgement has long been debated, particularly with regards evaluations concerning risk of reoffending, where actuarial risk assessment continue to outweigh expert opinion (Hanson \& Morton-Bourgon, 2009). On the other hand, since there are currently no known measures of permission-giving thoughts that are specifically tailored to CSEMOs, this study represents the first part of a development process that will build on professional judgement in terms of validating a structured assessment.

However, the focus on professionals can also be identified as a potential strength of this study. Firstly, research has identified that experienced professionals (i.e. psychologists involved in sex offender treatment), hold more positive attitudes towards sex offenders compared to individuals with less experience (Hogue, 1993; Sanghara \& Wilson, 2006). Thus, the permission-giving thoughts identified by the professionals in the present study are unlikely to be a result of negative biases towards the offenders. In addition, existing scales that measure permission-giving thoughts on children and sex have been developed either based upon previously developed measures or by individual authors, with no consultation from a wider group of professionals (Ward \& Keenan, 1999). In contrast, the underpinnings of the themes identified in this study are founded on the knowledge of 16 professionals, who have a range of experience in working with CSEMOs.

The themes identified in the present study are built on the professional opinions of forensic experts (as opposed to offender accounts), and as such, the results presented reflect only potential permission-giving thoughts relating to CSEMOs. At this stage, it is not yet clear if these hold validity (i.e., given that they are based on the participants' perception of the offenders' accounts, influenced by their subjective experience, understanding of the literature, etc.), if there is a hierarchy within the identified themes, and exactly which aspects represent cognitive distortions, or perhaps implicit theories. 
As such, the application of the themes to offenders can only be hypothesised at this stage, and thus it is essential that these themes are further developed and validated with offending populations.

\section{Practical implications}

The identification of these themes has the potential to be used in future research to further help in the understanding of CSEMOs and identify how their cognitions compare to CSOs. Future research should focus on exploring these themes in more detail, in understanding its components and underlying implicit theories. In addition, the above themes could be utilised to provide further support for the contact-driven versus fantasy-driven typology (Briggs et al., 2011; Merdian, Curtis, et al., 2013). With growing research supporting the aforementioned hypothesis (Beech, Elliott, Birgden, \& Findlater, 2008; Briggs et al., 2011; Merdian, Curtis et al., 2013), the development of a scale based upon the identified themes may be a fundamental tool to aid in the identification of these subgroups.

Moreover, the identification of CSEMOs cognitions may have a direct impact on working with CSEMOs in terms of assessment and treatment. Research has shown that endorsement of permission-giving statements are a crucial factor in the risk of sexual reoffending, and are thus frequently targeted in treatment (Andrews \& Bonta, 2006). This means that if the themes identified can be converted into items for a scale measuring permission-giving thoughts, this could provide an enhanced commentary on the general cognitions of CSEMOs. The development of such a scale could provide rich data that could be used to aid case formulations and identify the varying pathways to CSEM offending and the cross-over to contact sex offending.

\section{References}

Abel, G. G., Becker, J. V., \& Cunningham-Rathner, J. (1984). Complications, consent, and cognitions in sex between children and adults. International Journal of Law and Psychiatry, 7(1), 89-103. doi:10.1177/0093854894021002001

Andrews, D. A., \& Bonta, J. (2006). The psychology of criminal conduct (4th ed.) Newark, NJ: LexisNexis.

Babchishin, K. M., Hanson, R. K., \& Hermann, C. A. (2011). The characteristics of online sex offenders: A meta-analysis. Sexual Abuse: A Journal of Research and Treatment, 23(1), 92-123. doi:10.1177/1079063210370708

Babchishin, K. M., Hanson, R. K., \& VanZuylen, H. (2015). Online child pornography offenders are different: A meta-analysis of the characteristics of online and offline sex 
offenders against children. Archives of Sexual Behaviour, 44(1):45-66. doi:10.1007/s10508014-0270-x

Bates, A., \& Metcalf, C. (2007). A psychometric comparison of internet and non-internet sex offenders from a community treatment sample. Journal of Sexual Aggression, 13(1), 11-20. doi:10.1080/13552600701365654

Beck, A. T. (1963). Thinking and depression: Idiosyncratic content and cognitive distortions. Archives of General Psychiatry, 9, 324-333.

Beckett, R. C. (1987). The children and sex cognitions questionnaire. In K. Babchishin Using the Implicit Association Test to Assess Sexual Attraction to Children (Master's Thesis). Available from ProQuest Dissertations and Theses Database.

Beckett, R. C., \& Fisher, D. (1994, November). Assessing victim empathy: A new measure. Paper presented to the $13^{\text {th }}$ Annual Conference on the Association for the Treatment of Sexual Abusers, San Francisco, CA.

Beech, A. R., Bartels, R. M., \& Dixon, L. (2013). Assessment and treatment of distorted schemas in sexual offenders. Trauma, Violence, \& Abuse, 14(1), 54-66. doi: $10.1177 / 1524838012463970$

Beech, A. R., Elliott, I. A., Birgden, A., \& Findlater, D. (2008). The internet and child sexual offending: A criminological review. Aggression and Violent Behavior, 13(3), 216228. doi:10.1016/j.avb.2008.03.007

Beech, A. R., \& Mann, R. (2002). Recent developments in the assessment and treatment of sexual offenders. In J. McGuire (Ed.), Offender rehabilitation and treatment: Effective programmes and policies to reduce re-offending (pp. 259-288). Chichester: Wiley.

Blumenthal, S., Gudjonsson, G., \& Burns, J. (1999). Cognitive distortions and blame attribution in sex offenders against adults and children. Child Abuse and Neglect, 23(2), 129-143. doi:10.1016/S0145-2134(98)00117-3

Braun, V., \& Clarke, V. (2006). Using thematic analysis in psychology. Qualitative Research in Psychology, 3(2), 77-101. doi:10.1191/1478088706qp063oa

Briggs, P., Simon, W. T., \& Simonsen, S. (2011). An exploratory study of internet initiated sexual offenses and the chat room sex offender: Has the internet enabled a new typology of sex offender? Sexual Abuse: A Journal of Research and Treatment, 23(1), 72-91. doi:10.1177/1079063210384275

British Psychological Society. (2009). Code of Ethics and Conduct. Guidance published by the Ethics Committee of the 
British Psychological Society. Retrieved from

http://www.bps.org.uk/sites/default/files/documents/code_of_ethics_and_conduct.pdf

Bumby, K. M. (1996). Assessing the cognitive distortions of child molesters and rapists:

Development and validation of the MOLEST and RAPE scales. Sexual Abuse: A Journal of Research and Treatment, 8(1), 37-54. doi:10.1007/BF02258015

Burns, D. D. (1989). The feeling good handbook. New York, NY: William Morrow and Co.

Caple, T. (2008). A comparison of the characteristics and motivations of abusing and nonabusing child pornography offenders (Unpublished doctoral dissertation). James Cook University, Townsville, AUS.

Elliott, I. A., \& Beech, A. R. (2009). Understanding online child pornography use: Applying sexual offense theory to internet offenders. Aggression and Violent Behavior, 14(3), 180-193. doi:10.1016/j.avb.2009.03.002

Elliott, I. A., Beech, A. R., \& Mandeville-Norden, R. (2012). The psychological profiles of internet, contact, and mixed internet/contact sex offenders. Sexual Abuse: A Journal of Research and Treatment. doi:10.1177/1079063212439426

Elliott, I. A., Beech, A. R., Mandeville-Norden, R., \& Hayes, E. (2009). Psychological profiles of internet sexual offenders: Comparisons with contact sexual offenders. Sexual Abuse: A Journal of Research and Treatment, 21(1), 76-92. doi:10.1177/1079063208326929

Gannon, T. A., \& Polaschek, D. L. L. (2006). Cognitive distortions in child molesters: A reexamination of key theories and research. Clinical Psychology Review, 26(8), 10001019. doi:10.1016/j.cpr.2005.11.010

Gannon, T. A., Ward, T., \& Polaschek, D. L. L. (2004). Child sexual offenders. In M. Connolly (Ed.), Violence in society: New Zealand perspectives (pp. 34-48). Christchurch: Te Awatea Press.

Hanson, R. K., \& Morton-Bourgon, K. E. (2009). The accuracy of recidivism risk assessments for sexual offenders: A metaanalysis of 118 prediction studies. Psychological Assessment, 21(1), 1-21. doi:10.1037/a0014421

Helmus, L., Hanson, R. K., Babchishin, K. M., \& Mann, R. E. (2013). Attitudes supportive of sexual offending predict recidivism: A meta-analysis. Trauma, Violence \& Abuse, 14(1), 34-53. doi:10.1177/1524838012462244

Hogue, T. E. (1993). Attitudes towards prisoners and sexual offenders. In N. C. Clark \& G. Stephenson (Ed.), DCLP occasional papers: Sexual offenders (pp. 27-32). Leicester: British Psychological Society. 
Howitt, D., \& Sheldon, K. (2007). The role of cognitive distortions in paedophilic offending: Internet and contact offenders compared. Psychology, Crime \& Law, 13(5), 469-486. doi:10.1080/10683160601060564

Lee, A. F., Li, N., Lamade, R., Schuler, A., \& Prentky, R. A. (2012). Predicting hands-on child sexual offenses among possessors of internet child pornography. Psychology, Public Policy, and Law, 18(4), 644-672 doi:10.1037/a0027517

Mann, R. E., \& Marshall, W. L. (2009). Advances in the Treatment of Adult Incarcerated Sex Offenders. In A. R. Beech, L. A.

Craig, \& K. D. Browne (Eds.), Assessment and treatment of sex offenders: A handbook (pp. 329-347). West Sussex: John Wiley \& Sons.

Marshall, W. L., Anderson, D., \& Fernandez, Y. M. (1999). Cognitive behavioural treatment of sexual offenders. Chichester: John Wiley \& Son.

Marshall, W. L., Marshall, L. E., \& Kingston, D. A. (2011). Are the cognitive distortions of child molesters in need of treatment? Journal of Sexual Aggression, 17(2), 118-129. doi:10.1080/13552600.2011.580572

Maruna, S., \& Mann, R. E. (2006). A fundamental attribution error? Rethinking cognitive distortions? Legal and Criminological Psychology, 11(2), 155-177. doi:10.1348/135532506X114608

McCarthy, J. A. (2010). Internet sexual activity: A comparison between contact and noncontact child pornography offenders. Journal of Sexual Aggression, 16(2), 181-195. doi:10.1080/13552601003760006

Merdian, H. L., Curtis, C., Thakker, J., Wilson, N., \& Boer, D. P. (2013). The three dimensions of online child pornography offending. Journal of Sexual Aggression, 19(1), 121-132. doi:10.1080/13552600.2011.611898

Merdian, H. L., Curtis, C., Thakker, J., Wilson, N., \& Boer, D. P. (2014). The endorsement of cognitive distortions: Comparing child pornography offenders and contact sex offenders. Psychology, Crime and Law, 20(10), 971-993. doi:10.1080/1068316X.2014.902454

Merdian, H. L., Wilson, N., Thakker, J., Curtis, C., \& Boer, D. (2013). "So why did you do it?": Explanations provided by child pornography offenders. Sexual Offender Treatment, 8(1), 1-19.

Navathe, S., Ward, T., \& Gannon, T. (2008). Cognitive distortions in child sex offenders: An overview of theory, research and practice. Journal of Forensic Nursing, 4, 111-122. doi:10.1111/j.1939-3938.2008.00019.x 
Neidigh, L., \& Krop, H. (1992). Cognitive distortions among child sexual offenders. Journal of Sex Education \& Therapy, 18, 208-215.

Neutze, J., Seto, M. C., Schaefer, G. A., Mundt, I. A., \& Beier, K. M. (2011). Predictors of child pornography offenses and child sexual abuse in a community sample of pedophiles and hebephiles. Sexual Abuse: A Journal of Research and Treatment, 23(2), 212-242. doi:10.1177/1079063210382043

O’Brien, M. D., \& Webster, S. D. (2007). The construction and preliminary validation of the internet behaviours and attitudes

questionnaire (IBAQ). Sexual Abuse: A Journal of Research and Treatment, 19(3), 237-256. doi:10.1177/107906320701900305

Ó Ciardha, C., \& Gannon, T. A. (2011). The cognitive distortions of child molesters are in need of treatment. Journal of Sexual Aggression, 17(2), 130-141. doi:10.1080/13552600.2011.580573

Ó Ciardha, C., \& Ward, T. (2013). Theories of cognitive distortions in sexual offending: What the current research tells us. Trauma, Violence, \& Abuse, 14(1), 5-21. doi:10.1177/1524838012467856

Pollack, N. L., \& Hashmall, J. M. (1991). The excuses of child molesters. Behavioral Sciences \& the Law, 9, 53-59. doi:10.1002/bsl.2370090107

Quayle, E., Erooga, M., Wright, L., Taylor, M., \& Harbinson, D. (2006). Only pictures? Therapeutic work with internet sex offenders. Dorset: Russell House Publishing.

Radford, L., Corral, S., Bradley, C., Fisher, H., Bassett, C., Howat, N., \& Collishaw, S. (2011). Child abuse and neglect in the UK today. London: NSPCC.

Sanghara, K. K., \& Wilson, J. C. (2006). Stereotypes and attitudes about child sexual abusers: A comparison of experienced and inexperienced professionals in sex offender treatment. Legal and Criminological Psychology, 11(2), 229-244. doi:10.1348/135532505X68818

Seto, M. C., Hanson, K. R., \& Babchishin, K. M. (2011). Contact sexual offending by men with online sexual offenses. Sexual Abuse: A Journal of Research and Treatment, 23(1), 124-145. doi:10.1177/1079063210369013

Seto, M. C., Reeves, L., \& Jung, S. (2010). Explanations given by child pornography offenders for their crimes. Journal of Sexual Aggression, 16(2), 169-180. doi:10.1080/13552600903572396 
Surjadi, B., Bullens, R., Van Horn, J., \& Bogaerts, S. (2010). Internet offending: Sexual and non-sexual functions within a Dutch sample. Journal of Sexual Aggression, 16(1), 4758. doi:10.1080/13552600903470054

Taylor, M., Holland, G., \& Quayle, E. (2001). Typology of paedophile picture collections. The Police Journal, 74(2), 97-107.

Taylor, M., \& Quayle, E. (2003). Child pornography: An internet crime. Hove: BrunnerRoutledge.

Taylor, M., \& Quayle, E. (2005). Abusive images of children and the internet: Research from the COPINE project. In S. W. Cooper, R. J. Estes, A. P. Giardino, N. D. Kellogg, \& V. I. Vieth (Eds.), Medical, legal and social science aspects of child sexual exploitation: A comprehensive review of pornography, prostitution, and internet crimes (pp. 257-275). St Louis, MO: GW Medical Publishing.

Thornton, D. (2002). Constructing and testing a framework for dynamic risk assessment. Sexual Abuse: A Journal of Research and Treatment, 14, 139-153. doi:10.1177/107906320201400205

Ward, T. (2000). Sexual offenders' cognitive distortions as implicit theories. Aggression and Violent Behavior, 5, 491-507. doi:10.1016/S1359-1789(98)00036-6

Ward, T., \& Beech, A. (2006). An integrated theory of sexual offending. Aggression and Violent Behavior, 11(1), 44-63.doi:10.1016/j.avb.2005.05.002

Ward, T., \& Keenan, T. (1999). Child molesters' implicit theories. Journal of Interpersonal Violence, 14(8), 821-838. doi:10.1177/088626099014008003

Webb, L., Craissati, J., \& Keen, S. (2007). Characteristics of internet child pornography offenders: A comparison with child molesters. Sexual Abuse: A Journal of Research and Treatment, 19(4), 449-465. doi:10.1177/107906320701900408

Wilson, T. D. (2004). Strangers to ourselves: Discovering the adaptive unconscious. Cambridge, MA: Belknap Press. 